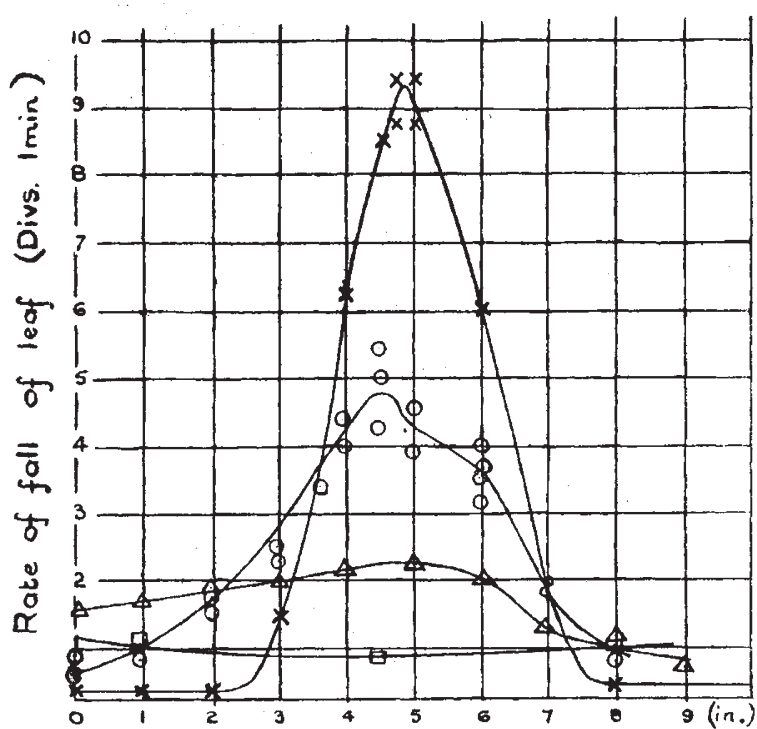

Dist. of sampling point from top of wind tunnel.

DISTRIBUTION OF RADON IN THE WAKE OF A POINT SOURCE. SAMPLING PROBE: AT POSITION $1 \mathrm{~A}, \times ;$ AT $2, \odot ; \mathrm{AT} 3, \triangle ;$ AT $6, \square$

not only for measurements of $l$ but alsu of the $c_{1}$ oss flow from one furnace port to another. By introducing the active gas suddenly it can ke used for the detection of regions of very low gas velocity; and by measuring the relative activity in a single pipe after perfect mixing is attained, it can ke used for metering hot raw gases continuously-a technical problem of very great difficulty and importance.

It is proposed to improve the technique by the use of an electrometer valve to increase the convenience of measurement for field work, and possibly by the development of continuous methods of removing the recoil atoms.

Our thanks are due to Dr. N. Feather, Prof. S. Russ and Mr. R. Siday for advice on the radioactive technique, and Mr. P. R. Chase for carrying out much of the experimental work; also to the Medical Research Council for the radon used in these experiments.

R. MAYORCAS.

M. W. Thring.

British Coal Utilisation Research Assoc.,

Experimental Station,

Rickett Street, London, S.W.6.

1 Goldstein, S., "Modern Developments in Fluid Dynamics" (Vol. 1), 214.

\section{A New Water-Soluble Polysaccharide from Perennial Rye Grass Pasture}

A WATER-SOLUBLE polysaccharide containing galactose and glucose residues has been isolated from perennial rye grass pasture. Repeated fractional precipitation from aqueous solution by alcohol and acid-alcohol followed by prolonged dialysis did not effect appreciable reduction of the high ash content (more than 30 per cent) of the polysaccharide. Since the ash consisted of calcium sulphate, it is suggested that the polysaccharide may occur as the calcium salt of the sulphuric ester of a polygalactose with one or more glucose residues incorporated in the carbohydrate moiety.

The aqueous solution of the polysaccharide was neutral in reaction, reduced Fehling's solution, and gave a positive rotation, $[\alpha] D^{16 \circ}+40^{\circ}(C=0.125)$.

The galactose was identified as mucic acid, m.p. and mixed m.p. $214^{\circ} \mathrm{C}$, and the glucose as acid potassium saccharate, which was converted to the silver salt. No other sugars were found.

All previously reported galactans appear to be of algal or fungal origin and the few known polysaccharide sulphuric esters, for example, agar', fucoidin ${ }^{2}$, etc., have been extracted from the same sources. On the other hand, the polysaccharide herein described is of higher plant origin.

Canterbury University College,

R. J. McIlroy.

Christchurch, C.1,

New Zealand. Aug. 18.

${ }^{1}$ Jones, W. G. M., and Peat, S., J. Chem. Soc., 225 (1942).

${ }^{2}$ Bird, G. M., and Haas, P., Biochem. J., 25, 403 (1931).

\section{Microbiological Assay of Riboflavin}

IN his letter appearing under the above title ${ }^{1}$, Dr. F. C. Happold criticizes the procedure used by $\mathrm{Dr}$. E. C. Barton-Wright and Mr. R. G. Booth ${ }^{2}$ in the determination of rikoflavin, and insists on the importance of calcium in the nutrient medium and mentions the work of Chattaway, Happold and Sandford ${ }^{3}$. The evidence in the latter paper to which he evidently refers consists in an experiment in which a series of increasing doses of calcium chloride was added to the nutrient medium. The authors do not seem to have appreciated fully a limiting factor in the very low solubility of calcium in the presence of excess of phosphate at $p \mathrm{H} 6 \cdot 6-6 \cdot 8$. The solubility product of tricalcium phosphate is akout $10^{-32}$, but may ke perhaps $10^{-31}$ in the presence of the other minerals contained in Chattaway, Happold and Sandford's nutrient medium 4,5 .

Calculation shows that the quantity of calcium soluble under the conditions of their experiment is the equivalent of $0.0028 \mathrm{ml}$. of 0.5 per cent calcium chloride in the $20 \mathrm{ml}$. of medium used, whereas additions ranging from 0.1 to $0.8 \mathrm{ml}$. were made. Virtually the whole of the added calcium would be precipitated. It is true that the addition of calcium chloride was delayed until after sterilization of the main part of the medium, but subsequent precipitation during the seventy-two hours at $37^{\circ}$ may be taken as certain. In the absence of precise knowledge of certain factors-the time taken for such precipita tion to occur, how soon inoculation followed the pre. paration of the flasks of medium, whether or not precipitation preceded the main growth of the bacteria, and if so its effect on the latter when settling to the bottom of the flasks, etc. - it is impossible to state what effects were exercised by the added calcium. At least it seems certain that the diroct conclusion that calcir $m$ stimulates growth of the Lactobacillus is not warranted by the experimental evidence cited.

University of Birmingham.

R. H. HoPkINS.

Nov. 8.

1 Happold, F. C., NATURE, 152, 414 (1943).

2 Barton-Wright, E. C., and Booth, R. G., Biochem. J., 37, 25 (1948)

${ }^{3}$ Chattaway, F. W., Happold, F. C., and Sandford, Mary, Biochem. J. 37,298 (1943).

"Holt, E., La Mer, V. K., and Chown, H. B., J. Biol. Chem., 64, 500 (1925).

'Hopkins, R. H., and Amphlett, P. H., J. Inst. Brew., 45, 365 (1939) 